\title{
O delírio como método: a poética desmedida das singularidades.
}

\section{The delirium as method: the immeasurable poetic of singularities}

\section{Tania Mara Galli Fonseca*}

Professora dos Programas de Pós-graduação em Psicologia Social e Institucional e de Informática Educativa da Universidade Federal do Rio Grande do Sul - UFRGS, Porto Alegre, RS, Brasil

\section{Luis Artur Costa**}

Doutorando no Programa de Pós-Graduação em Informática na Educação da Universidade Federal do Rio Grande do Sul - UFRGS, Porto Alegre, RS, Brasil

\section{Vilene Moehlecke ***}

Doutoranda do Programa de Pós-Graduação em Informática na Educação da Universidade Federal do Rio Grande do Sul - UFRGS, Porto Alegre, RS, Brasil

\section{José Mário Neves****}

Doutorando no Programa de Pós-Graduação em Informática na Educação da Universidade Federal do Rio Grande do Sul - UFRGS, Porto Alegre, RS, Brasil

\begin{abstract}
RESUMO
Esse artigo busca compor uma problematização do método de produção de conhecimento e intervenção em Psicologia, com intuito de construir formas de apreensão inventivas. Pensamos um modo cartográfico que se dobra entre o sensível e o inteligível, ao desdobrar sentidos e operar no plano das multiplicidades. Assim, podemos mapear o plano das singularidades, que flui em uma superfície de Acontecimentos cujo efeito pode produzir o contágio da lógica dos paradoxos e suas complexidades intensivas. Aqui, a cartografia pretende traçar as linhas de tais contaminações. Desse modo, tentamos pensar o método em sua poésis, abrimos mão de um método previsível e feito por procedimentos universalizantes, para nos tornarmos efeitos de superfície e experimentarmos as complexidades da linguagem e de suas proliferações. Finalmente, lembramos a potência do simulacro, que assegura a concepção do mundo a partir da estética: a este mundo cabe investigar e intervir com operadores poéticos, questionando e criando retóricas existenciais, estilísticas do ser.
\end{abstract}

Palavras-Chave: Cartografia, Singularidades, Poética, Linguagem, Simulacro. 


\begin{abstract}
This article intends to compose a questioning of the knowledge's production method and practice in Psychology, in order to construct ways of inventive understanding. For this, we think about a cartographic mode that folds between the sensitive and intelligible, when it spread senses and operate in the way of multiplicities. So we can map the plane of singularities, which flows in an area of Events which can produce the contagion effect of the logic of the paradoxes and complexities intensive. At this point, the mapping aims to trace the lines of such contamination. Thus, we think about the method in his poetic, and we open hand a predictable method done by universalizing procedures. We intend to become the purpose of surface and to experience the complexities of language and its proliferations. Finally, we affirm the power of simulacre, which ensures the conception of world through aesthetics: we may investigate this world and speak with operator poetic, in order to question and to create rhetorical style of being.
\end{abstract}

Keywords: Cartography, Singularities, Poetic, Language, Simulacre.

\title{
1. Abrindo cartografias
}

A problematização contemporânea dos princípios metodológicos estabelecidos pela filosofia iluminista e desenvolvidos no decorrer da modernidade é uma das operações que permitiu a construção de um novo campo epistêmico. Ultrapassar a simplificação formalista, a redução, voltar o método para outros sentidos, além da previsão e controle, tornaram-se partes dos objetivos a serem alcançados pelos pesquisadores das ciências humanas. O desafio, agora, não seria mais a busca de uma natureza racional, mas a impregnação sensível de suas lógicas embrulhadas, bem como a conexão dos atributos relançados ao hibridismo da imanência. Para tanto, somos convocados a construir novas tramas e a mapear as crises que geram uma estranha permanência daquilo que passa e sofre alterações diversas, a tecermos uma densa geografia dos afetos, como uma cartografia das dobras entre - sensível e o inteligível, plano múltiplo que reconecta a heterogeneidade das forças e formas.

Assim, no método cartográfico, construímos formas de compreensão delirantes que ultrapassam as divisões entre o entendimento (razão), o sentimento (afetos) e a sensação (empírico). Ao construirmos formas de ser na pesquisa, relativas à construção de nossa problemática, erigimos o que aqui denominaremos tecnologias do sensível: agenciamentos maquínicos que constituem ritornelos do pesquisar (FONSECA; COSTA; KIRST, 2008). Trata-se de pequenas máquinas de produção de mundos que se constroem no campo do impessoal. Ou seja, pensamos uma produção de modos pautada pela impureza do sensível e pelo desmedido da imaginação através de uma poética do desejo. 


\section{Um método de pensamento e abertura para psicólogos}

$\mathrm{Na}$ tentativa de romper com o paradigma da simplicidade, que volta a atenção para o homogêneo, ou para a clareza das coisas, direcionamos o olhar para os interstícios, isto é, para um meio híbrido que promove uma nova discussão e um olhar sensível sobre a vida. Assim, ao invés de operar em uma lógica de síntese e análise, que divide o objeto para dele extrair suas idéias certeiras, apostamos nas complexas ligações que investem sujeito e objeto e transformam a ambos, uma vez que são traçadas outras conexões entre afetos e imagens. A partir desse modo de construção do olhar, a pesquisa também se volta para o intempestivo jogo dos sentidos e acontecimentos misturados, na tentativa de compor novas reflexões e mergulhos sobre os mundos que nos afetam.

Desse modo, a Psicologia não pode se fechar a essas vibrações, pois, nesse caso, ela correria o risco de se tornar mera reprodução de verdades já reveladas. Perguntamos, pois, como abrirmos o campo psi para novas emblemáticas e perfurações de seus fazeres e dizeres? Como apostar em uma Psicologia que se torna sensível aos acontecimentos e aos encontros com um plano caótico e vivo, produtor de crises e novos enredos para o sujeito e a vida?

Talvez, uma pista seria a própria busca de intercessores em nossos modos de pensar e intervir na construção de idéias e práticas mais conectadas com as transformações que nos envolvem. Como afirma Deleuze (1992, p. 156): "O essencial são os intercessores. A criação de intercessores. Sem eles não há obra". Portanto, os intercessores podem ser produzidos entre a ciência, a arte e a filosofia, pois se tratam de séries misturadas, ou de uma série de vários termos, tais quais potências do falso que provocam rupturas. Podemos, então, fabricar os próprios intercessores, como um corte que nos faz pensar, sejam eles "fictícios ou reais, animados ou inanimados".

Assim, buscamos intercessores entre a Psicologia e a Filosofia, a fim de provocar fissuras nos modos de pensar psi e abrirmos seu campo para novas sensibilidades e encontros. Quando operamos em suas linhas fronteiriças, estamos próximos de uma aventura inventiva, pois somos tomados por uma espécie de curiosidade e zelo para aquilo que altera as formas a priori.

Ora, se entendemos que os movimentos da subjetividade são nômades e transitórios, em suas vibrações vamos pousar a nossa atenção, para que, desse encontro singular, seja possível a construção de uma nova sistemática de sentido. Em meio à complexidade do pensar, abrimos o sensível e o inteligível ao corpo e às reconfigurações singulares do ser, aos intercessores criados, para estarmos mais atentos aos movimentos do desejo que produz sujeitos e os transformam em novos modos de si. 
Desse modo, o método de produção de conhecimento da Cartografia, que se apóia em bases conceituais da Filosofia da Diferença, pode nos auxiliar nessa aventura epistemológica, ao criar redes entre conceitos e acontecimentos, bem como experimentar um plano de alteridade que liga pensamento e afecção. Não se trata, pois, de um protocolo de ações pré-definidas, mas de um mergulho na experiência, que lança o pesquisador a novas tramas e o convida a transitar em um campo aberto e fugaz, que faz nascer as estratégias de ação e de pensar, ampliando os leques de intervenção do conhecer.

Entendemos, pois, que a Psicologia pode beber de tais fontes, visto que o desafio da produção de conhecimento sobre a subjetivação nos impele a romper com o simples ou o complicado, para buscarmos um pensamento em sua complexidade e abertura, que nos impulsione a pensar sobre a produção de diferença presente na subjetividade e no contemporâneo. Mexemos, assim, na concepção de sujeito, como se fosse algo já definido, para acompanharmos os processos sutis e emblemáticos de uma estilística do ser que se constrói a partir de movimentos nômades e ligados a uma contextualização específica e transitória.

A partir dessas questões, podemos operar com os conceitos da Filosofia da Diferença, a fim de interferir nos modos de produção de conhecimento da Psicologia, já que o complexo nos impele a novas construções de sentido. Além disso, ao ampliarmos o olhar sobre os movimentos da subjetivação, também nos lançamos ao desafio de alterar as nossas formas de intervir, uma vez que o tecnicismo em Psicologia não dá conta das novas redes ação e existência que cercam os movimentos contemporâneos.

No momento em que lançamos uma práxis psi nesse plano de problematização e questionamento, temos a chance de compor uma espécie de método delirante, que não busca as verdades prontas, mas se enreda nas perguntas que acionam um emaranhado de operadores conceituais e nos instrumentalizam para novas lógicas de ação. Nesse sentido, não buscamos um caminho único, mas podemos nos tornar mais sensíveis à criação de estratégias e ações, para ir ao encontro das novas demandas da subjetivação e de uma escuta ampliada.

Propomos, pois, a construção de tais elos, com o intuito de relançarmos o método de pesquisa e de intervenção ao encontro com novos modos de pensar e olhar o mundo, já que os psicólogos também buscam uma transformação em seus estilos de trabalhar as problemáticas do ser. Mais do que aplicação de um saber, apostamos na desenvoltura do olhar e das práticas, quando operamos com conceitos envoltos em complexidade e criação. Somos tomados por esses desafios, para 
investir na produção de diferença da própria Psicologia, além de cartografar as transformações do sujeito e da composição de novas possibilidades para a construção de um intervir mais aberto aos movimentos do desejo. Abrimos, pois, o corpo da pesquisa e da práxis, a fim de mergulhar em novas problemáticas e operar redes de afeto entre conceitos e modos de ação.

\section{Operando a escala da carta: a cosmogênese no plano das singularidades}

A cartografia, que é definida por Kastrup (2007) como "um método formulado por G. Deleuze e F. Guattari (1995) que visa acompanhar um processo, e não representar um objeto" caracteriza-se como um método inusitado não tanto pelas "metodologias e procedimentos" que propõe os quais já apresentam um surpreendente caráter inovador no campo psi - mas sim pela "escala" de observação, análise e operação proposta. Na definição de uma nova "escala" de operação do trabalho da pesquisa, encontramos a grande invenção metodológica de Deleuze e Guattari e é desta definição que decorrem as principais determinações do método.

A cartografia define-se por uma "escala" paradoxal de operação - a escala das singularidades: ao invés de dimensionar-se a partir das generalidades populacionais e de espécie ou a partir do caso, do sujeito, e do indivíduo ${ }^{1}$, a cartografia opera um plano paradoxal que se coloca para além destas medidas opostas, molares e homogêneas. Nesse sentido, como observa Deleuze (2006a, p.105-106), "Não podemos aceitar a alternativa que compromete inteiramente ao mesmo tempo a psicologia, a cosmologia e a teologia: ou singularidades já tomadas em indivíduos e pessoas ou o abismo indiferenciado".

As singularidades constituem o plano do "acontecimento". Nesse plano, não temos nem o caos do "abismo indiferenciado" onde seria impossível pensar qualquer determinação, nem individualidades já formadas; mas singularidades anônimas e nômades, impessoais, pré-individuais. Mesmo sem apresentar o grau de determinação do ser individuado, as singularidades não se caracterizam pela indeterminação e indiferenciação. Nesse sentido, observa Schöpke (2004, p.38):

Para Deleuze, o campo das singularidades é algo que se interpõe entre o "fundo negro" e o mundo físico, entre o caos e os corpos. Lugar da superfície dos acontecimentos, lugar do verdadeiro transcendental da natureza.

Interposto entre o caos e o mundo empírico, este é o plano das dimensões intensivas das multiplicidades - das afetações moleculares, 
dos agenciamentos, dos contágios, das ressonâncias -, que a cartografia busca acessar, mapear e agitar.

Deleuze (1988, p. 438) define as singularidades como "o ponto de partida de uma série que se prolonga sobre todos os pontos ordinários do sistema até a vizinhança de uma outra singularidade; esta engendra uma outra série que ora converge, ora diverge em relação à primeira"ponto de partida que se caracteriza como "ponto-dobra", "ponto de inflexão", que, segundo Deleuze (1991, p. 33),

[...] é o puro Acontecimento da linha e do ponto, o Virtual, a idealidade por excelência. Efetuar-se-á segundo eixos de coordenadas, mas, por enquanto, não está no mundo: ela é o próprio Mundo, ou melhor, seu começo, dizia Klee, "lugar da cosmogênese", "ponto não-dimensional", ponto "entre as dimensões".

As singularidades, estes "signos ambíguos", são os operadores do contágio, na medida em que qualquer singularidade pode afetar e ser afetada por qualquer outra, já que não estão submetidas aos limites e requisitos impostos pelos processos de convergência das séries, que governa o plano das individualidades - e que implica uma dialética da negatividade e da exclusão do contraditório - produzindo uma condição de fechamento e definição de uma identidade. Por seu lado, as singularidades operam o contágio segundo uma lógica do paradoxo, cuja potência de afetar e de ser afetado independe da semelhança e da convergência, pois elas entram em ressonância e se comunicam por suas diferenças e distâncias.

Os bandos, humanos e animais, apontam Deleuze e Guattari (1997, p.23), "proliferam com os contágios, as epidemias, os campos de batalha e as catástrofes". A cartografia busca traçar as linhas dessas contaminações, fazer um mapa desses campos de batalha, narrar as dramáticas dessas núpcias, talvez seja melhor dizer, desses devires que estão aquém e além da lógica do terceiro excluído. Contaminações, batalhas e núpcias que acontecem ponto-a-ponto, mas que no seu acontecer colocam em ressonância, fazem vibrar uma nova música que reverbera em toda a série.

Não se trata de uma geografia horizontal abrangendo grandes territórios, ou vertical aprofundando-se em intimidades locais. Trata-se de uma espacialização transversal, que atravessa de viés e opera um desvio das leituras instituídas no campo psi. Tal transformação do espaço busca acessar algo que é único sem pertencer a um único sujeito ou tipo, uma linha que atravessa irregularmente, de modo intermitente, um território 
que é de todos e de ninguém. Isto é, aquilo de mais geral e específico a um só tempo, sem nenhum destes ser: o impessoal.

Nessa nova geografia, as singularidades constituem os potenciais que determinam a metaestabilidade dos sistemas, conforme destaca Deleuze (2006a, p.106):

As singularidades-acontecimentos correspondem a séries heterogêneas que se organizam em um sistema nem estável nem instável, mas "metaestável", provido de uma energia potencial em que se distribuem as diferenças entre as séries.

Assim, tomar as singularidades como operadores da cartografia implica um ajuste "perceptivo-conceitual", que descole o "olhar-escuta" do plano das molaridades e consiga tocar o campo dos potenciais e tensões impessoais e pré-individuais, o plano do sentiendum, que é o que há para sentir, sendo a fronteira insensível - plano que se encontra no ponto limite onde se processa o retorno dentro-fora, no qual o insensível torna-se sensível e vice-versa.

Desse modo, é no movimento em torno desse ponto limite, na sua permanente ultrapassagem, que se produz o infinito e que a dobradura do real se instaura plena de novidade. O real, então, expande-se em novas realidades-mundos, cujas direções são disparadas pelo pulsar de infinitas singularidades. Na cinesia dessa dobradura, no fluxo dessa ultrapassagem, a cartografia busca sintonizar, fazer-se sensível, deixarse afetar.

Dessa maneira, a cartografia "substitui" a lógica das substâncias e dos atributos - tão conforme ao pensamento da representação - por uma lógica do acontecimento - que se instaura no limite do apreensível, como encontro de linhas e de fluxos de pontos dispersos em velocidade infinita. Decorrente desta "substituição" lógica, a cartografia dirige-se para as singularidades impessoais e pré-individuais, no lugar das conceitualidades e individualidades, e opera um deslocamento da "atenção" 2 do plano do atual para o do virtual. Neste sentido, Villani (2000, p.46) define como a "anomalia metafísica da filosofia deleuziana", o interesse que "vai objetivamente para as multiplicidades virtuais e intensas, para as singularidades, e nunca para as conceitualidades, nem para as individualidades".

A cartografia evidencia-se, assim, como um método que não está voltado a apreender o que está dado, o Um, o Mesmo; mas sim, o que insiste, o que está às portas do presente forçando-o e pedindo passagem. Um método que não busca tal apreensão como um ato de dominação - com a pretensão de recortar um segmento do mundo, 
congelado na definição de um "objeto científico" -, mas como um ato de "captação", como uma apreensão que se dá como luta e como núpcias, como um encontro no qual se trava uma batalha e/ou um enlace amoroso, um devir a-paralelo no qual cartógrafo e mundo disparam-se mutuamente para novas criações e movimentos. Assim, o cartógrafo experimenta-se a si mesmo nos encontros que provoca e nos que the são impostos pelo campo. Não se trata, porém, de encontros de sujeitos e de objetos, e sim da experimentação de acoplamentos fractais de singularidades, que se define como uma experimentação permanente de mobilidade de fronteiras.

Nos marcos dos encontros, não cabe falar de neutralidade, pois não apenas a direção da pesquisa está plenamente modulada pelo pesquisador cartógrafo, como também o próprio desenvolvimento do campo e suas efetuações estão profundamente implicados pela pesquisa. O mero ato de atribuir estatuto de problema de pesquisa a um tema ou problema pode significar uma importante intervenção num campo determinado campo. Temos, portanto, também instaurado um perspectivismo radical, para o qual o pesquisador não se coloca a tarefa de representar um suposto campo objetivo, como mais um ponto de vista sobre um campo que se supõe sempre o mesmo; pelo contrário, trata-se de um campo no qual a pesquisa infiltra-se produzindo divergência e bifurcação, "como se uma paisagem absolutamente distinta correspondesse a cada ponto de vista", como observa Deleuze (2006a, p.266) a respeito da obra de arte moderna.

Se não há mais uma verdade essencial, determinada pelo grau de semelhança com o modelo para definir o ser e, portanto, passível de ser descoberta ou revelada, conforme sentenciou Deleuze ${ }^{3}$, resta-nos pensar o ser como expressividade existencial, como uma estilística, um "modo de ser". Uma nova forma de definir um ser que não pode mais ser colocado fora do devir, um ser que não existe mais apenas em si, que não só está no tempo do mundo, mas também no mundo do tempo, um ser que é mundo, que é engendrado a cada encontro mundano, inclusive no encontro com a pesquisa cartográfica. Aqui, a cartografia beira a ontologia, faz-se ontogênese. Uma pesquisa assim concebida, sem a pretensão de "descobrir" ou de "revelar" uma realidade ou um objeto dado, torna-se um poderoso, mas despretensioso, método de produção/invenção de conhecimento. $\mathrm{E}$, na medida em que se faz ciente da infinidade pulsante no plano de imanência, transforma-se em atrator de virtualidades que pedem passagem. 


\section{Operando aberturas sensíveis: poética-poiese}

Descartes (1999) vence o solipsismo de sua dúvida com o chão duro da razão sem corpo, pura abstração auto-referente a pairar em um vazio que será preenchido por suas eternas idéias geométricas e matemáticas perfeitas. Nesta aventura de vencer as ilusões de sarcásticos demônios zombeteiros, abandona a espada flamejante do arcanjo e a troca por uma lâmina de frias luzes com o fio mais fino que o da navalha de Ockan e passa a partir as coisas e colocá-las em seus devidos lugares. Para além do empirismo caótico e intuitivo dos aristotélicos e sua vassoura de cerdas desaprumadas Bacon (1999), agora seria possível dar "chumbo à imaginação", pregando-a à promessa do Método Moderno. Para tanto, era necessário não apenas delimitar o campo empírico, dado e estrito, como também era preciso erigir um método totalmente lúcido, pura razão pura de formas perfeitas e simétricas tal qual os paralelogramas da inteligência divina agostiniana. E como à imagem do Deus de Santo Agostinho fomos feitos: pura intelecção, entendimento, apenas consciência sem corpo seríamos em essência. Definida nossa racional natureza racional, basta então definir nossos demais atributos e anulá-los de algum modo: fluídos animais, afetos e imaginação deveriam ser iluminados pelo inteligível: "E não se deve inventar ou imaginar o que a natureza faz ou produz, mas descobri-lo" (BACON, 1999, p.109). Assim, mirando para o empírico diante de nós, nossa alma pode ativamente extrair o inteligível campo próprio ao conhecimento.

Enquanto a sensação é o efeito da pressão dos objetos exteriores sobre os órgãos dos sentidos, os quais por sua vez levam suas impressões até o cérebro, a imaginação é apenas uma capacidade de fazer permanecer estas aparências dos objetos em nossa mente, sendo a nomenclatura latina para o que os gregos chamavam fantasia (HOBBES, 1999). Tratase, portanto, do delírio do entendimento, posto que “[...] o objeto é uma coisa, e a imagem ou ilusão outra" (HOBBES, 1999, p. 32). É apenas a razão que permite a sanidade dos sentidos, fazendo-os ir além das aparências até as essências gerais e eternas.

Por outro lado, as certezas buscadas também podem limitar a complexidade da vida, uma vez que elas nos impõem certa sobriedade para com o mundo. E, diante de suas artimanhas, aceitamos a sua solidez. Há, porém, um pulsar que escapa aos códigos e normas prescritas, já que relança os sentidos a novas produções e descobertas. Um encontro entre séries divergentes invade a nossa suposta orientação, ao tirarmos o ser do amornamento ilusório de que o mundo nos pertence, ou de que a distinção entre o pensar e o sentir seria necessária. Nesse ponto, o sentido, embriagado de sua atualidade, 
encharca-se com novas tramas e cores, e se joga no embate múltiplo entre afeto, razão e fragmento inventado. Com isso, abrimos mão de um método previsível e feito por procedimentos universalizantes, para nos tornarmos efeitos de superfície e experimentarmos as complexidades da linguagem e de suas proliferações.

Para Deleuze (2006a, p.10), a antiga profundidade se desdobrou na superfície, e o "devir ilimitado se desenvolve agora inteiramente nesta largura revirada". Não importa, pois, o que vem antes, ou o que gera o ser, mas a sua meta-estabilidade, o desequilíbrio transformado em reviravolta de simulacros. Reviramos, então, as causas ou a previsibilidade das coisas, para nos recobrirmos com novos agenciamentos, tramas inventadas entre elementos múltiplos que se desdobram e invadem o saber e o não saber, numa narrativa feita de mistérios e aberturas ao intempestivo movimento da vida, tornada maquinação e aventura.

Nesse movimento inusitado, compomos brechas, entre o saber e o nonsense, tal qual uma trama inventada que precisa de uma nova configuração. E, mais do que buscar as respostas, deixamos que as perguntas se contaminem com o problemático entorno daquilo que não se sabe, daquilo que ainda não tem existência, mas que insiste, persiste, no jogo duplo dos sentidos inventados. A previsibilidade e o procedimento perdem a importância, já que o método se enlaça à trama dos sentidos misturados, naquilo que o porvir define a cada encontro em contaminação com o outro.

Desse modo, ao pensarmos no inteligível, que era concebido enquanto puramente racional e abstrato, podemos agora considerar sua constituição híbrida e paradoxal, que o torna também sensível: a abstração age no mundo e sua ação não é apenas concreta, como também está para além do racional, envolvendo os afetos e as afecções do corpo. Do mesmo modo, o que chamamos de sensível, e que era considerado a pura sensação, concretude variável no tempo, passa a ser também inteligível, a pensar e a problematizar junto ao corpo que também é mente, mentindo mundos verdadeiros vários, construídos por estas forças para além da divisão entre entendimento e sensação, epistemologia e ontologia.

Em meio a um plano composto de elementos heterogêneos, o pensar se contamina com o sentir, ambos tornam-se cúmplices de um estranhamento repentino, que os convocam a uma abertura e a uma nova imbricação. Nesse devaneio inventado, o corpo encontra o incorpóreo, como se desejasse a sua própria abstração, levada à mais alta potência, roubada de seu antigo vigor, transformada em vertigem sutil. O pensar se enreda com o Fora, nesse plano Impessoal e múltiplo, 
que carrega, em si, um repertório de sentidos misturados, no tempo de Aion, dos Acontecimentos que provocam tensão e ruptura.

Assim, não se trata da especulação de um mundo interno que sobe à superfície, tampouco buscamos o descobrimento de uma verdade em essência. Ao cartografar, tentamos produzir os deslizes do eu, bem como o desmanche daquilo que já fazia sentido, para que, dessa falha, seja possível convocar a perfuração de mundos e o seu próprio estremecimento. Nesse aspecto, cartografamos as desmesuras da paisagem e escrevemos aquilo que transborda o sentir e o pensar, tal qual um devaneio que encontra uma casa e se transforma em abstração colocada em sonho. Conforme Foucault (2006, p.268), na escrita, não se trata da amarração do sujeito em uma linguagem, "trata-se da abertura de um espaço onde o sujeito que escreve não pára de desaparecer". O sensível se envolve com o conhecer, há um entrelaçamento de idéias e ações. Pesquisamos, então, aquilo que nos convoca e atormenta, e tornamo-nos cúmplices de suas audácias e desatinos.

Dessa finitude e estranheza, a noção de obra também se transforma, uma vez que a marca do escritor, ou do pesquisador, nasce da singularidade de sua ausência. Escrevemos, ou pesquisamos, no limite daquilo que não sabemos, ou do que já não somos mais. Vivemos o tormento de transitar entre o sonho e a aventura da maquinação de sentidos. E, nesse jogo caótico, pensamento e sensação se imbricam numa estória embrulhada, ao fazerem coexistir as séries divergentes e ao diferir enredos entrelaçados. O método pode, então, compor uma dobra das composições da existência, ao costurar os nós entre afeto, cognição e abertura cósmica.

Logo, a criação, a invenção, fatores antes relegados ao ostracismo epistêmico, passam a fazer parte das operações de construção do conhecimento e constituição de intervenções. Intervir, aqui, implica a interferência, o corte, a ruptura que convém ao corpo, ao relançá-lo às aventuras de experimentação do pensamento. Nesse intrépido estilo cartográfico, podemos compor as narrativas dos encontros inventados e saborear as delícias de um recomeço tornado origem menor, gênese inventada, sujeito infame. Por meio de inquietações e desconhecimentos, abrimos o corpo para a sua fissura, para aquilo que o torna estranhamento e dúvida. No limite das ausências inventadas, escrevemos ou compomos a descoberta do mundo, perante sua insaciável solidão e ternura.

Assim, a ficção passa a ser o fundamento do documental, a criação do dado e o delírio do bom senso: "O delírio está no fundo do bom senso, razão pela qual o bom senso sempre é segundo" (DELEUZE, 1988, p. 
363). Perante o dado tornado menor, razão segunda, podemos sofrer com o intempestivo do acaso, tal qual um lance de dados que convoca à variação. Devemos, portanto, fazer delirar às coisas, aos modos, subvertendo seus regimes e provocando clinamens que abrem os fluxos.

\begin{abstract}
Em termos bastante genéricos dizemos que há duas maneiras de invocar "destruições necessárias": a do poeta, que fala em nome de uma potência criadora, apto a reverter todas as ordens e todas as representações, para afirmar a Diferença no estado de revolução permanente do eterno retorno; e a do político, que se preocupa, antes de tudo, em negar o que "difere" para conservar, prolongar uma ordem estabelecida na história ou para estabelecer uma ordem histórica que já solicita no mundo as formas de sua representação. (DELEUZE, 1988, p. 101)
\end{abstract}

Nessa luta, temos a chance de fazer voltar todo o delírio que se enlaça aos avessos da história, na tentativa de contá-la de múltiplos modos, para além da previsibilidade das descobertas. Operamos a ética de um retorno que volta os possíveis à sua mais elevada potência, para relançar a força criadora de afirmação de um porvir. Uma ética condicional supõe a chama dos enredos inventados de múltiplos modos e transforma o encontro entre narrativa e poética. Assim, o imperativo do como se pode tomar conta do corpo: viva como se cada instante voltasse eternamente, elevando a mais alta potência o desejo de criação, e tornando o tempo a molecularização da existência replicada em configurações diversas. Optamos por uma abertura que supõe a éticaestética da existência, daquilo que já não somos mais, do que estamos nos tornando, tal qual uma invenção de mundos estranhos e abertos a fluxos nômades. O desafio consiste em viver como se o delírio do verbo voltasse eternamente, ao fazer estremecer as relações entre o falar e o sentir.

Desse modo, vemos delinear-se a poética como operação potencializadora dos possíveis na cartografia. Partindo de “[...] uma idéia de poesia sempre excessiva" (DELEUZE, 1988, p.457), vamos pensar a poética como a poiética do desmedido, daquilo que transborda os sistemas de aceitabilidade e provoca novas intuições que tomam ao corpo de assalto em novas imagens, novos gestos. Assim, o corpo encontra o incorpóreo, jogo extremo de superfícies ao avesso que se enlaçam e convocam a forma a se distorcer. Uma chama envolve a crítica e provoca ações no pensamento, tornado passagem, envolto no excesso e na sensação maquínica das intensidades. Nessa mistura de heterogêneos, forma e força se afetam e dançam a melodia do extremo, como uma nova suavidade lançada ao acaso e tornada método de conhecer e inventar o mundo em sua potência de expressão e desenlace. 
O humor, a farsa, o non-sense, o absurdo e o paradoxo permitem, pela arte, liberar os simulacros do grave jugo da representação: "A obra de arte abandona o domínio da representação para tornar-se 'experiência', empirismo transcendental ou ciência do sensível" (DELEUZE, 1988, p. 107). Um jogo ardiloso invade a certeza e provoca a desmesura, a degradação da verdade, aberta a novas possibilidades e ações. Não representamos, pois, o dito, mas envolvemos o não-dito ao eterno retorno de suas reverberações e promiscuidades.

Com a afirmação poética do desmedido, afirmamos uma política delirante onde o paradoxo dá o tom para a orgia sensível que se instaura. I mporta, em nossa operação, sua poética efetuação poética, o erigir modos impuros, tomados do absurdo espantoso que provê o tônus do poeta: é girando manco, bêbado em meio à dança, que se instaura a metaestabilidade gonza que vai sempre de viés cerzindo um tracejado incerto. Afirmar a poesia e o risco: "Como diz Nietzsche, entre os justos a afirmação é primeira, [...] Eis porque as verdadeiras revoluções têm também um ar de festa" (DELEUZE, 1988, p.424). Pensar da poesia que problematiza em virtualizações a ultrapassagem da constituição de descrições e reduções formalistas: pensar de poesia que faz misturas alquímicas e aguarda a poção explodir em suas mãos.

Não se trata da ciência da arte nem da arte da ciência, falamos antes de um híbrido formado na junção escancarada destes: arte e ciência, ciência-arte, arte-ciência. Poderíamos inclusive abandonar de uma vez por todas a partícula ciência desta equação e dá-la sem ciúme, em baixela de prata adornada aos que buscam sempre serem seus únicos donos. Esta linha de tecnologia do sensível (FONSECA; COSTA; KIRST, 2008) que se afirma entre a ciência e a arte não se apresentam como uma novidade em nosso campo, pois diversas são as experimentações que já aconteceram neste sentido: o olho câmera de Dziga Vertov, a cartografia delirante da Roma de Fellini, as instalações fotográficas entre os Lapões de Jorma Puranen, os estudos do movimento anamorfomáticos de Marey, as projeções subversivas de Shimon Attie em Berlin. Tomar ao som, à imagem, ao corpo, à escrita, entre outras ações, enquanto possibilidade de expressão de mundos, levando em consideração suas inevitáveis inteligibilidade sensível e sensível inteligibilidade: ponto brumoso do paradoxo. "A manifestação da filosofia não é o bom senso, mas o paradoxo" (DELEUZE, 1988, p.364). Nesse limiar, o paradoxo corre nos dois sentidos, ao mesmo tempo, entre o tempo de cronos, cronologia linear das coisas, e o tempo de Aion, Acontecimento das virtualidades em composição. Assim, fazemos o método trabalhar, na direção da coexistência entre arte e conhecimento, ou entre linguagem e não-senso. Este, para Deleuze 
(1998), não implica a ausência de sentido, mas diz o seu próprio sentido, na composição de um murmúrio híbrido, aberto aos acasos que se envolvem e produzem novas rupturas e reverberações. O elemento paradoxal torna-se não-senso e envolve a bifurcação das séries, envoltas em complexidades e diferenças. Não buscamos a clareza das coisas, mas a sua perpétua bifurcação e o embaralhamento de sentidos. Dispomos de um pequeno saber, envolto num emaranhado de virtualidades e desconhecimentos, que o interpelam e o desvirtuam de antigas argumentações.

Nesse trânsito complexo, os dados são relançados às suas virtualidades, num tempo que se reinventa e se torna nova dobra do mundo. Compomos, não a escrita de um presente, mas algo entre o que acabou de se passar, ou que vai se passar, tal qual um tempo rachado e cindido em presentes múltiplos, conectados por um passado-futuro por vir. Traçamos a arte dos recomeços, ou a poética das expressões envoltas em alegrias e mistérios. Tentamos viver, então, a aventura das escritas maquínicas, revestidas de estórias embrulhadas. E, ao fazer reverberar o verbo e a sintaxe, jogamos o sentido numa trama de coexistências nômades que se contagiam e revelam a força das superfícies misturadas. Segundo Deleuze (2006a), propomos uma linguagem em superfície que doa sentidos e mexe numa fronteira caótica, entre as proposições e as coisas. Assim, um sentido é produzido na circulação entre séries singulares e heterogêneas, que se subdividem ao infinito e se enlaçam e novas possibilidades e perpetuações. Entre a heterogênese das séries, pode nascer um novo recomeço, uma espécie de ética dos Acontecimentos que se envolve ao corpo do verbo e doa novo ritmo às palavras.

Da poética, a sintaxe se bifurca em proliferações absurdas e beira as bordas de um sentido inventado e relançado à sua embriaguez. Assim, corpo e verbo fazem dobra, e convocam o delírio a transbordar os limites da linguagem e a atormentar os infinitivos com novas idéias e proliferações. Nesse espirituoso murmúrio de indagações, cartografamos o intempestivo jogo de afetos e produções desejantes, que fazem sentido na corda bamba entre o pensamento e a invenção: "No começo era o verbo, só depois é que veio o delírio do verbo. [...] A criança não sabe que o verbo escutar não funciona para cor, mas para som. Então se a criança muda a função de um verbo, ele delira" (BARROS, 1998a, p.25)

\section{Estilísticas: a ontologia estética dos modos}

As operações poéticas inserem o absurdo onde a linearidade e a conexão lógica imediata regiam. Fazem vibrar uma onda anômala de 
contágio que agita às singularidades nômades. Tal agitação poética das singularidades faz ressoar no impessoal uma melodia bastarda, dissonante perante o cânone da harmonia, levando ao corpo vibrações intempestivas que abrem novos possíveis. Vemos, então, o surgimento de séries rebeldes, séries que se afirmam para além e aquém de modelos, sejam eles uma idéia inteligível ou mesmo uma coisa como referente substancial. A expressão e o sentido não mais se reduzem a uma representação atrelada ao referente primeiro através do cordão razoável da verossimilhança. Adquirindo por si o status de ser, a partir de suas ações no mundo, subvertem a própria noção de mundo, produzindo outro pensamento que macula a natureza estável de um modo pensado pela forma e substâncias com a introdução da paradoxalidade imanente: "Não é próprio do simulacro ser uma cópia, mas reverter todas as cópias, revertendo também os modelos: todo pensamento torna-se uma agressão" (DELEUZE, 1988, p.17).

Assim, não há o ponto de origem, do qual a expressão seria serva, que sirva de baliza ao expurgo dos bastardos e sua degradada relação de parentesco com a ontologia: o eterno retorno opera a dissolução da origem e do original, instituindo uma sucessão ilimitada de cópias, tudo retorna como cópia de si, aquém e além de modelos representativos e identitários. "Cada coisa, animal ou ser é levado ao estado de simulacro [...]" (DELEUZE, 1988, p.122). Tudo se tornou simulacro, e o simulacro não consiste na reprodução, na imitação de um modelo, mas sim, no próprio ato de reversão que subverte esta hierarquia binária: diluindo a oposição entre cópia e original, modelo e imitação, expressão e referente, etc.

Os simulacros ultrapassam a dualidade das proposições entre designação de coisas e expressão de sentido, acolhendo aos efeitos, aos sentidos, às ações e às expressões, como se mais que coisas fossem. Colocamo-nos, então, para além da reificação do ser em forma ou substância, posto que estes se dissolvem nos fluxos: a própria expressão já é. O problema da ausência de designação, de referente no mundo das coisas, representações ou modelos inteligíveis, não é mais uma barreira ao simulacro. Importa sim seus efeitos, suas expressões: sua potência poética é sua força poiética e vice-versa ${ }^{4}$. "Como diz Bergson, não vamos dos sons às imagens e das imagens ao sentido: instalamo-nos logo de saída em pleno sentido" (DELEUZE, 2006a, p.31). Assim, o(a) fundamento da expressão não se encontra na ponta de um dedo infantil a requerer e inquirir o sentido de um seio. Posto que nem o dedo é ponta, nem o seio coisa, mas ambos são na expressão de um apontar, sem origem primeira ou fim último que lhes dê os contornos do fundamento da designação. 
Outra natureza é aí constituída, a ontologia se descola da substância e da forma compreendidas como causas do ser que produz as expressões. Tudo se torna efeito, em um mundo de ações que se relacionam sem a necessidade de um agente imóvel: “Portanto, atrás das máscaras há ainda máscaras" (DELEUZE, 1988, p.179). O disfarce e as máscaras nada mais são do que operações de deslocamento virtual entre as séries. Assim sendo, são as máscaras e os disfarces que dão corpo às expressividades dos problemas. É o problemático e a imanência que operam a univocidade e a contemporaneidade das séries divergentes, já que estas têm ao caos como único ponto de "convergência original": tornando inviável a diferenciação entre original e cópia. É o eterno retorno que opera o fundo sem fundo, o a-fundamento destas séries divergentes, onde não é o mesmo que retorna, mas sim o distinto, a diferença: a única constante é de variação.

A passagem do pseudo à superfície torna-o não mais um ser acanhado afeito aos cantos onde a luz da verdade e o chinelo do juízo se fazem ausentes; antes, perde o caráter de pecado e o simulacro passa a ser o seu efeito, a ação que provoca e constitui as superfícies da vida: a potência do falso é seu efeito. Tomado como ação, efeito, expressão, não há mais cobrança de coerência interna, mas sim atenção às relações que constitui em seus agenciamentos: os estilos que cria em sua trajetória. Quando do pecado original, quando o homem abandonou a divindade do verbo e abraçou a carne animal e suas vibrações desumanas, quando decaímos em um simulacro de Deus, restando apenas sua imagem e não sua semelhança tornamo-nos simulacros e, a partir disso, não importou mais a nossa verdade essencial, mas sim o estilo, a retórica de nossa expressividade existencial. "Tornamo-nos simulacros, perdemos a existência moral para entrarmos na existência estética" (DELEUZE, 2006a, p.263). É exatamente esta natureza estética do simulacro que assegura aqui a concepção do mundo a partir da estética: a este mundo cabe investigar e intervir com os operadores poéticos, questionando e criando retóricas existenciais, estilísticas do ser. Nessa trama, o mundo se faz profano e mundano, rodeado de vazios e proliferações. O não-senso invade o sentido e provoca insanidades lingüísticas, rodeadas de estilo e vizinhança estética. Em suas rachaduras, podemos supor um movimento de contemplação inventiva, no momento em que a degradação do degradado supõe uma alteração menor, um pequeno simulacro, tal qual uma molécula transmutada em nova expressividade. Operamos, então, com o mapeamento das fissuras e suas chances de irradiação de diferenças.

Dessa forma, a repetição na arte não é a cópia da vida, a arte não imita a vida e vice-versa, a arte desloca a substância fluída da vida, 
problematiza-a, apresentando-se não como pretendente de suas verdades, mas antes se avivando arte e artificializando-se vida, acentuando na vida a vertigem dos simulacros.

Isto porque não há problema estético a não ser o da inserção da arte na vida cotidiana. Quanto mais nossa vida parece standartizada [...], mais deve a arte ligar-se a ela e dela arrancar esta pequena diferença. (DELEUZE, 1988, p.460)

Assim, vida e estética podem se imbricar, num entrelaçamento de heterogêneos que supõe o plano do inteligível e do sensível em diferença e conexão recíproca, como assevera Barros (1998b, p. 81) "Pelos meus textos sou mudado mais do que pelo meu existir".

Conforme Deleuze (2006b), podemos pensar a dramatização como um método. Ela se faz por meio de dinamismos espaço-temporais, que supõem um movimento forçado, em direção a um sujeito larvar, a um campo de individuação e de séries de diferenças intensivas. Aquilo que força supõe um duplo envolvimento entre corpos e singularidades, que se enredam e provocam um encontro entre diferenças e intensidades. Trata-se, pois, de um estranho teatro feito de determinações puras, que agitam espaço e tempo, agem sobre a alma, tem larvas por atores. Nesse ponto, um modo de ser larvar recoloca o ser em contato com o rastejar de sua existência, em direção a novos percalços e virtualidades. A larva carrega, em si, a potência embrionária da criação de novos possíveis relançados a uma estética da existência. Em meio a um movimento tomado por uma lentidão plástica, um modo larvar se mistura com o meio e se associa a novas expressividades.

Deparamo-nos com modos larvares e fugazes que escorregam de si e serpenteiam frente ao inacabamento das coisas, ao suportar vazios e dramas. Para Deleuze (2006b), é o conhecimento científico, o sonho e também as coisas em si que dramatizam. Num jogo caótico de afetos e perceptos, o virtual coexiste ao atual e supõe corpos transmutados num porvir de novos enredos e inquietações. O conceito diz de si e, ao mesmo tempo, desdiz a sua história, rompe com a significação que já não lhe serve. Onde se quebram, pois, os limites de uma ciência que desdenha a própria verdade e se torna moribunda de generalizações, uma vez que acessa um repertório de novos possíveis e se avizinha com estéticas e tecnologias de si?

Assim, a um determinado conceito, podemos procurar e compor o drama a que ele corresponde. A coexistência do atual e do virtual implicam uma melodia cósmica que faz o método tremer as bases e brincar com as próprias replicações. Um plano caótico de singularidades 
pré-individuais invade os modos de conhecer, bem como de se tornar sujeito. Abrimos o abstrato e o religamos com as concretudes construídas, num ímpeto infame por novos ritmos para o pensamento. Fazemos tremer o sentido e o sensível, numa espécie de zona intermediária entre afeto e política cognitiva inventiva.

Abre-se agora a possibilidade de debruçar-se sobre o usual objeto da psicologia social de outra maneira. O desafio consiste em perceber no cotidiano o costume, não como as regras formais que balizam o movimento das formigas em seu dia-a-dia, mas mirar o costume como a estilística da fantasia criada neste carnaval diário e vulgar em sua imanência e comunalidade. Trata-se, então, de mapear o jogo de simulação e aventura que atravessa o hábito e o torna vítima contemplativa de sua própria transfiguração. Com isso, o comum, o infame, o que se repete, carrega também a potência de variação e recomeço, origem segunda de uma diferença inventada e vivida de incontáveis modos.

Em um método psi que desliza dos procedimentos certeiros e se enreda no não saber e no desencantamento, a dúvida ganha consistência e reverberação. $O$ objeto se torna abandonado de seus mundos, entregue ao acaso e também ao movimento forçado que busca uma política larvar de cognição e maquinação da vida. E, em meio à entrega de si, o corpo sussurra palavras recriadas e experimenta vazios que o tiram de antigas lamentações. O expresso não se esconde na profundidade, mas se faz a partir de um deslizamento contínuo e imanente à vida. Ele desliza na movimentação de si, absorto em riscos e novas tentativas de duplicar imagens e proposições. Por isso, a linguagem atual também é povoada por seus dramas, por um plano de virtualidades e singularidades impessoais, que podem desdobrar, a qualquer momento, o sentido e seus múltiplos.

Possibilitar, por exemplo, problematizar o balé dos movimentos rotineiros e compreender sua singular aventura de leveza, no lugar de somente imprimir-lhes seus verdadeiros sentidos ocultos nas mínimas minúcias geométricas cotidianas. Nesse ponto, o cotidiano dança diante dos olhos de um transeunte distraído, ao inventar piruetas carregadas de orgia e excentricidade. Ao mesmo tempo, a leveza consiste em fazer o problemático criar novos passos, entrelaçados com ritmos e melodias inventadas. O método pode desejar a problemática coreografia de possíveis que se recria a cada ensaio, aberta a uma suposta expressão intensiva.

Desse modo, esperamos mirar suas imagens poéticas sem detratá-las como meras miragens esmerilhadas por um prestidigitador, apenas seguir as linhas que compõem seus turbilhões, o cerzir de suas relações. 
As paisagens configuram-se como resoluções dos agenciamentos territoriais. Paisagens existenciais são os modos de ser da subjetividade, problematizados exatamente no ponto onde indiferenciam o olhar e o que é visto. Olhar e paisagem formam um ponto cego em seu encontro, no qual ambos se criam.

Nesse enlace paradoxal, a poética se imprime, mas também exprime suas reviravoltas e perplexidades. O indivíduo não se compõe em uma relação figura e fundo com a paisagem, mas constitui-se como puro efeito da própria paisagem, produto e produtor de atualizações de sua imanência. Em suma, busca-se pensar com a poética, em última instância, como o plano da vida se cria e a potência em dispersão virótica de variação entre as singularidades constitui as estilísticas: variações de variações.

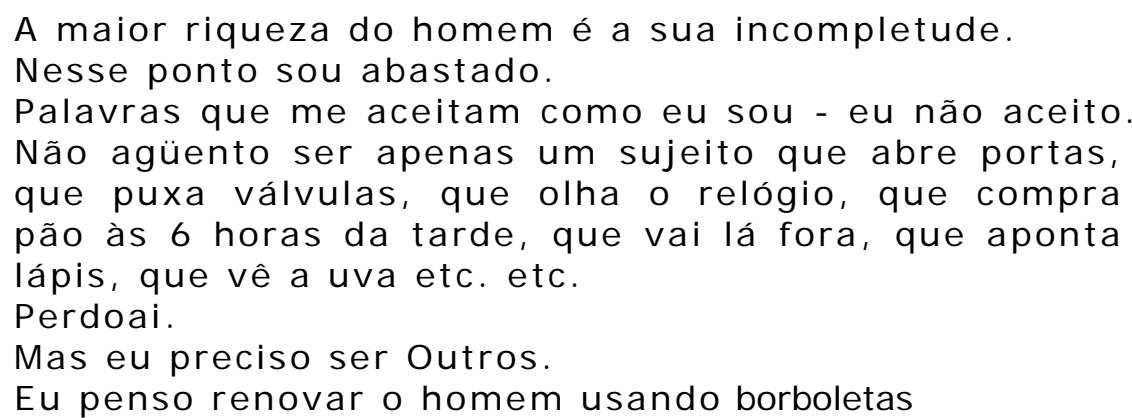

(Manuel de Barros, 1998b, p. 79).

\section{Referências Bibliográficas}

BACON, F. Novum Organum. (Coleção Os pensadores). São Paulo: Ed. Nova Cultural, 1999.

BARROS, M. O livro das ignorãças. Rio de Janeiro: Record, 1998a.

$\overline{1} 9 \overline{9} \mathrm{~b}$.

. O retrato do artista quando coisa. Rio de Janeiro: Record,

DELEUZE, G. Diferença e repetição. Rio de Janeiro: Graal, 1988.

A dobra: Leibniz e o barroco. Campinas: Papirus, 1991.

Conversações. São Paulo: Ed. 34, 1992.

Lógica do sentido. São Paulo: Perspectiva, 2006a.

A ilha deserta: e outros textos. São Paulo: Iluminuras, 2006b.

DELEUZE, G.; GUATTARI, F. Mil platôs: capitalismo e esquizofrenia, v. 4. São Paulo: Ed 34, 1997.

DESCARTES, R. Meditações. (Coleção Os pensadores). São Paulo: Nova Cultural, 1999. 
FONSECA, T. G.; COSTA, L. A.; KIRST, P. G. Ritornelos para o pesquisar no contexto das tecnologias virtuais do sensível. Revista Informática na educação: teoria e prática, Porto Alegre, 2008, v.11, n.1. Disponível em:

$<$ http://www.seer.ufrgs.br/index.php/InfEducTeoriaPratica/> Acesso em: 21 jul. 2009.

FOUCAULT, M. Ditos e Escritos III - Estética: literatura e pintura, música e cinema. Rio de J aneiro: Forense Universitária, 2006.

HOBBES, T. Leviatã. (Coleção Os pensadores). São Paulo: Nova Cultural, 1999.

KASTRUP, V. O funcionamento da atenção no trabalho do cartógrafo. Revista Psicologia e Sociedade, v.19, n.1, Porto Alegre, jan/abr2007. Disponível em:

http://www.scielo.br/scielo.php?script=sci_arttext\&pid=S0102$71822007000100003 \& \mathrm{lng}=\mathrm{pt \& nrm}=\mathrm{iso}>$. Acesso em: 11 maio 2009.

SCHÉRER, R. Homo Tantum. O impessoal: uma política. In: ALLIEZ, E. (Org.). Gilles Deleuze: uma vida filosófica. São Paulo: Ed. 34, 2000, p. 21-38

SCHÖPKE, R. Por uma filosofia da diferença: Gilles Deleuze o pensador nômade. Rio de Janeiro: Contraponto; São Paulo: EDUSP, 2004.

VILLANI, A. Deleuze e a anomalia metafísica. In: ALLIEZ, E. (Org.). Gilles Deleuze: uma vida filosófica. São Paulo: Ed. 34, 2000, p. 3948.

\footnotetext{
Endereço para correspondência

Tania Mara Galli Fonseca

Programa de Pós-Graduação em Informática na Educação, Universidade Federal do Rio Grande do Sul, Av. Paulo Gama, 110, prédio 12105, 3o andar, sala 332, CEP 90040060, Porto Alegre-RS, Brasil

Endereço eletrônico: tfonseca@via-rs.net

Luis Artur Costa Porto Alegre

Programa de Pós-Graduação em Informática na Educação, Universidade Federal do Rio Grande do Sul, Av. Paulo Gama, 110, prédio 12105, 3o andar, sala 332, CEP 90040060, Porto Alegre-RS, Brasil

Endereço eletrônico: lartur@cpovo.net

Vilene Moehlecke

Programa de Pós-Graduação em Informática na Educação, Universidade Federal do Rio Grande do Sul, Av. Paulo Gama, 110, prédio 12105, 3o andar, sala 332, CEP 90040060, Porto Alegre-RS, Brasil

Endereço eletrônico: vilene@univates.br

José Mário Neves
} 
Programa de Pós-Graduação em Informática na Educação, Universidade Federal do Rio Grande do Sul, Av. Paulo Gama, 110, prédio 12105, 3o andar, sala 332, CEP 90040 060, Porto Alegre-RS, Brasil

Endereço eletrônico: jmario.neves@gmail.com

Recebido em: 27/07/2009

Aceito para publicação em: 06/11/2009

Acompanhamento do processo editorial: Deise Mancebo, Marisa Lopes da Rocha, Roberta Romagnoli.

\section{Notas}

* Psicóloga, doutora em educação, coordenadora do grupo de pesquisas Corpo, Arte e Clínica nos modos de trabalhar e subjetivar.

**Psicólogo, mestre em Psicologia Social e Institucional na UFRGS; pesquisador do grupo Corpo, Arte e Clínica/UFRGS.

***Psicóloga, mestre em Psicologia Social e Institucional na UFRGS e mestrado sanduíche em Filosofia na Universidade Nova de Lisboa, com bolsa da ALBAN; atua como psicóloga do CAPS Capilé/São Leopoldo; professora da UNIVATES, no curso de Psicologia e na Especialização em Dança, Corpo e Arte; membro do grupo de estudos Corpo, Arte e Clínica/UFRGS, São Leopoldo, Brasil.

****Psicólogo, mestre em Psicologia Social e Institucional/UFRGS; Pesquisador do grupo Corpo, Arte e Clínica; autor do livro A Face Oculta da Organização: a microfísica do poder na gestão do trabalho, pela Editora UFRGS e SULINA.

${ }^{1}$ Schérer (2000, p.21) assinala que temos, entre os principais temas do pensamento de Deleuze, "uma substituição, desse sujeito e mesmo de uma individualidade ainda por demais maciça, por demais 'molar', de uma pessoa artificial, ou mesmo puramente alegórica, por 'singularidades' moleculares, moventes ou 'nômades'".

${ }^{2}$ A palavra atenção está colocada entre aspas para destacar que não se trata de uma mera "focalização", mas, como observa Kastrup (2007) sobre a atenção: "Seu funcionamento não se identifica a atos de focalização para preparar a representação das formas de objetos, mas se faz através da detecção de signos e forças circulantes, ou seja, de pontas do processo em curso".

${ }^{3}$ Neste sentido, Deleuze (2006b, p. 106) afirma: "Subverter o platonismo significa o seguinte: recusar o primado de um original sobre a cópia, de um modelo sobre a imagem. Glorificar o reino dos simulacros e dos reflexos".

${ }^{4}$ Acompanha-se a potência poética da poiética do paradoxo e vice-versa na sua operação sobre a expressão com as aliterações (repetição que não constitui redundância, mas sim diferença), as palavras-coisa (designa o que expressa e expressa a si, sem que seu sentido esteja em outra palavra como usualmente ocorre, flertando assim com o não senso) e as palavras-valise: "Cada parte virtual de uma tal palavra designa o sentido da outra, ou expressa a outra parte que, por sua vez, o designa" (DELEUZE, p.70, 2006). 